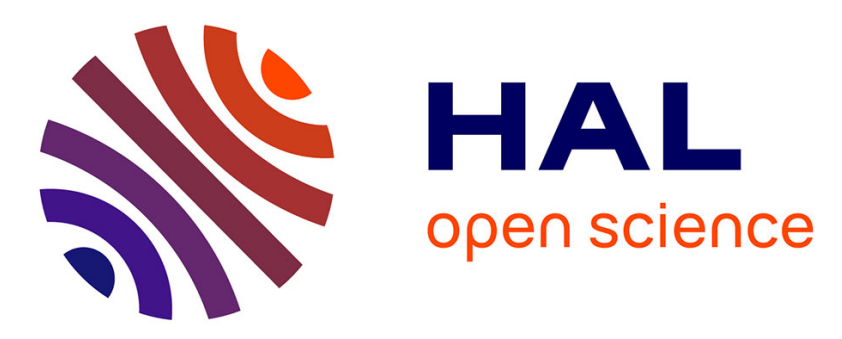

\title{
Sodium-Calcium-Magnesium Exchange Reactions on a Montmorillonitic Soil: II. Ternary Exchange Reactions
}

Philip Fletcher, Kenneth M Holtzclaw, Claire Jouany, Garrison Sposito, C André Lévesque

\section{- To cite this version:}

Philip Fletcher, Kenneth M Holtzclaw, Claire Jouany, Garrison Sposito, C André Lévesque. SodiumCalcium-Magnesium Exchange Reactions on a Montmorillonitic Soil: II. Ternary Exchange Reactions. Soil Science Society of America Journal, 1984, 48 (5), pp.1022-1025. 10.2136/sssaj1984.03615995004800050014x . hal-02725026

\section{HAL Id: hal-02725026 \\ https://hal.inrae.fr/hal-02725026}

Submitted on 2 Jun 2020

HAL is a multi-disciplinary open access archive for the deposit and dissemination of scientific research documents, whether they are published or not. The documents may come from teaching and research institutions in France or abroad, or from public or private research centers.
L'archive ouverte pluridisciplinaire HAL, est destinée au dépôt et à la diffusion de documents scientifiques de niveau recherche, publiés ou non, émanant des établissements d'enseignement et de recherche français ou étrangers, des laboratoires publics ou privés. 


\title{
Sodium-Calcium-Magnesium Exchange Reactions on a Montmorillonitic Soil: II. Ternary Exchange Reactions ${ }^{1}$
}

\author{
Philip Fletcher, Kenneth M. Holtzclaw, Claire Jouany, Garrison Sposito, and C. S. LeVesque ${ }^{2}$
}

\begin{abstract}
The exchange of magnesium for calcium at $298 \mathrm{~K}$ on a montmorillonitic soil separate (principally clay and silt) was investigated in a $50 \mathrm{~mol} \mathrm{~m}^{-3}$ perchlorate background at $\mathrm{pH} 5,6$, and 7. The charge fraction of sodium in the aqueous solution phase was controlled at 0.70 or 0.85 during the exchange experiments, resulting in average exchangeable sodium percentages ranging from 5 to $25 \%$ on the soil. Exchange isotherms for magnesium indicated some preference on the soil for calcium over magnesium. This preference was attributed primarily to the presence of organic matter associated with the soil separate. However, the exchange isotherms showed no effect of $\mathrm{pH}$ in the range between 5 and 7 , and no effect of exchangeable sodium percentage in the range between 0 and $25 \%$.
\end{abstract}

Additional Index Words: cation exchange, exchangeable sodium percentage, pH effect on cation exchange, soil salinity.

Fletcher, I., K.M. Holtzclaw, C. Jouany, G. Sposito, and C.S. LeVesque. 1984. Sodium-calcium-magnesium exchange reactions on a montmorillonitic soil: II. Ternary exchange reactions. Soil Sci. Soc. Am. J. 48:1022-1025.

$\mathrm{T}$ HE exchange of $\mathrm{Mg}^{2+}$ for $\mathrm{Ca}^{2+}$ at $25^{\circ} \mathrm{C}$ on specimen montmorillonite suspended in a $50 \mathrm{~mol} \mathrm{~m}^{-3}$ perchlorate background at $\mathrm{pH} 7$ was investigated recently by Sposito et al. (1983) in respect to the effect of exchangeable sodium percentage (ESP). In the ESP range between 0 and $36 \%$, the clay was found to exhibit equal affinities for $\mathrm{Ca}^{2+}$ and $\mathrm{Mg}^{2+}$ within the precision of the experiments (Sposito et al., 1983, Fig. 1). A similar result has been reported by Levy et al. (1983), who showed that the ratio of $\mathrm{Mg}$ charge fraction to $\mathrm{Ca}$ charge fraction on specimen montmorillonite initially at zero ESP tended not to shift significantly after equilibration of the clay with $200 \mathrm{~mol}$ $\mathrm{m}^{-3} \mathrm{NaCl}$ to produce an ESP of about $27 \%$. Both of these studies lend support to the long-standing hypothesis that, on arid-zone soil clays, $\mathrm{Ca}^{2+}$ and $\mathrm{Mg}^{2+}$ show essentially identical exchange selectivities (Bresler et al., 1982).

In this paper, the selectivity question addressed by Sposito et al. (1983) for pure montmorillonite is investigated for a montmorillonitic soil separate associated with organic matter. The exchange of $\mathbf{M g}$ for $\mathrm{Ca}$ at ESP values between 0 and $25 \%$ is studied in a $50 \mathrm{~mol} \mathrm{~m}^{-3}$ perchlorate background maintained at $\mathrm{pH}$ 5,6 , or 7 . The principal objective of the research was to determine the effect of ESP (in the range of practical importance) on the affinity of the soil separate for $\mathrm{Ca}$ and $\mathrm{Mg}$. Fletcher et al. (1984) found that Ca was preferred slightly over $\mathrm{Mg}$ at zero ESP using the same soil separate as in the present study. Moreover, the exchange isotherms determined by Fletcher et al. (1984) at $\mathrm{pH} 6,6.6$, and 7 were congruent, indicating no effect

\footnotetext{
${ }^{1}$ Contribution from the Dep. of Soil and Environmental Sciences, Univ. of California, Riverside, CA 92521. Received 23 Jan. 1984. Approved 30 Apr. 1984.

${ }^{2}$ Postdoctoral Research Soil Scientist, Research Associate IV, Postdoctoral Research Soil Scientist, Professor of Soil Science, and Research Associate III, respectively.
}

of proton competition on the selectivity relationship. A similar kind of soil exchange investigation at nonzero ESP does not appear to have been published heretofore, although Robbins et al. (1980) have reported data pertaining to $\mathrm{Ca}-\mathrm{Mg}$ exchange at $\mathrm{pH}$ values between 6 and 7 on two Entisols in the presence of adsorbed $\mathrm{Na}$ and $\mathrm{K}$. These two soils, which contained only illite and kaolinite in the clay fraction, showed preference for $\mathrm{Ca}$ over $\mathrm{Mg}$ at ESP values in the narrow range of 0 to $4 \%$ which resulted from the composition of the waters used to irrigate the soils. No attempt was made to study the effect of ESP in a broader range under controlled conditions of $\mathrm{pH}$ and ionic background medium as in the present experiments.

\section{MATERIALS AND METHODS}

\section{Soil Separate}

A sample of Altamont clay loam (fine, montmorillonitic, thermic Typic Chromoxererts) was used in this study. The $\mathrm{pH}$ value of the saturated soil paste is 5.7 and the content of organic $C$ in this soil is $2.9 \pm 0.1 \%(w / w)$. The cation exchange capacity of the soil is $0.38 \mathrm{~mol}\left(\mathrm{p}^{+}\right) \mathrm{kg}^{-1}$ at $\mathrm{pH} 8.2$. The procedures used to obtain a soil separate consisting almost entirely of clay and silt and to prepare the separate in the sodium-saturated form have been described in detail by Fletcher et al. (1984). The soil-separate batches had an average organic $C$ content of $2.6 \pm 0.7 \%(w / w)$.

\section{Exchange Experiments}

Sodium-soil samples were reacted at $25 \pm 0.3^{\circ} \mathrm{C}$ with ternary mixed salt solutions of $\mathrm{NaClO}_{4} / \mathrm{Ca}\left(\mathrm{ClO}_{4}\right)_{2} / \mathrm{Mg}\left(\mathrm{ClO}_{4}\right)_{2}$ following the general procedure described by Fletcher et al. (1984). The total perchlorate concentration was maintained within $10 \%$ of $50 \mathrm{~mol} \mathrm{~m}^{-3}$ in all experiments. In one series of exchange experiments $s_{2}$ the charge fraction of $\mathrm{Na}$ in the aqueous solution phase $\left(E_{\mathrm{Na}}\right)$ was 0.70 and the $\mathrm{pH}$ value was maintained at $6.0 \pm 0.2$ or $7.02 \pm 0.06$. In another series of experiments, $\widetilde{E}_{\mathrm{Na}}$ was 0.85 and the $\mathrm{pH}$ value was $4.7 \pm$ $0.3,5.8 \pm 0.1$, or $6.9 \pm 0.2$.

\section{Soil Concentration}

\section{Chemical Analysis}

The concentration of Na-soil in the stock suspension was determined as described by Sposito et al. (1981). The concentration of the Na-soil suspension was $44.0 \pm 0.0 \mathrm{~g}$ soil $\mathrm{kg}^{-1}$ suspension.

\section{Supernatant and Soil Slurry Composition}

Each of the three replicate supernatant solutions in an exchange experiment was analyzed for $\mathrm{Na}$ by flame emission and for $\mathrm{Ca}$ and $\mathrm{Mg}$ by flame absorption on a Perkin-Elmer Model 5000 atomic absorption spectrophotometer. The three soil slurries recovered in each experiment were analyzed for their content of $\mathrm{Na}, \mathrm{Ca}, \mathrm{Mg}$, and water as described by Sposito et al. (1983) and Fletcher et al. (1984).

\section{Data Analysis}

The surface excesses and moles of adsorbed charge of $\mathrm{Na}$, $\mathrm{Ca}$, and $\mathrm{Mg}$ were calculated as described by Sposito et al. (1981). The total adsorbed metal charge in a perchlorate 
FLETCHER ET AL.: SODIUM-CALCIUM-MAGNESIUM EXCHANGE REACTIONS ON A MONTMORILLONITIC SOIL: II. 1023

Table 1-Experimental data on Na-Ca-Mg exchange at $\tilde{E}_{\mathrm{Na}}=0.70$ on Altamont soil.

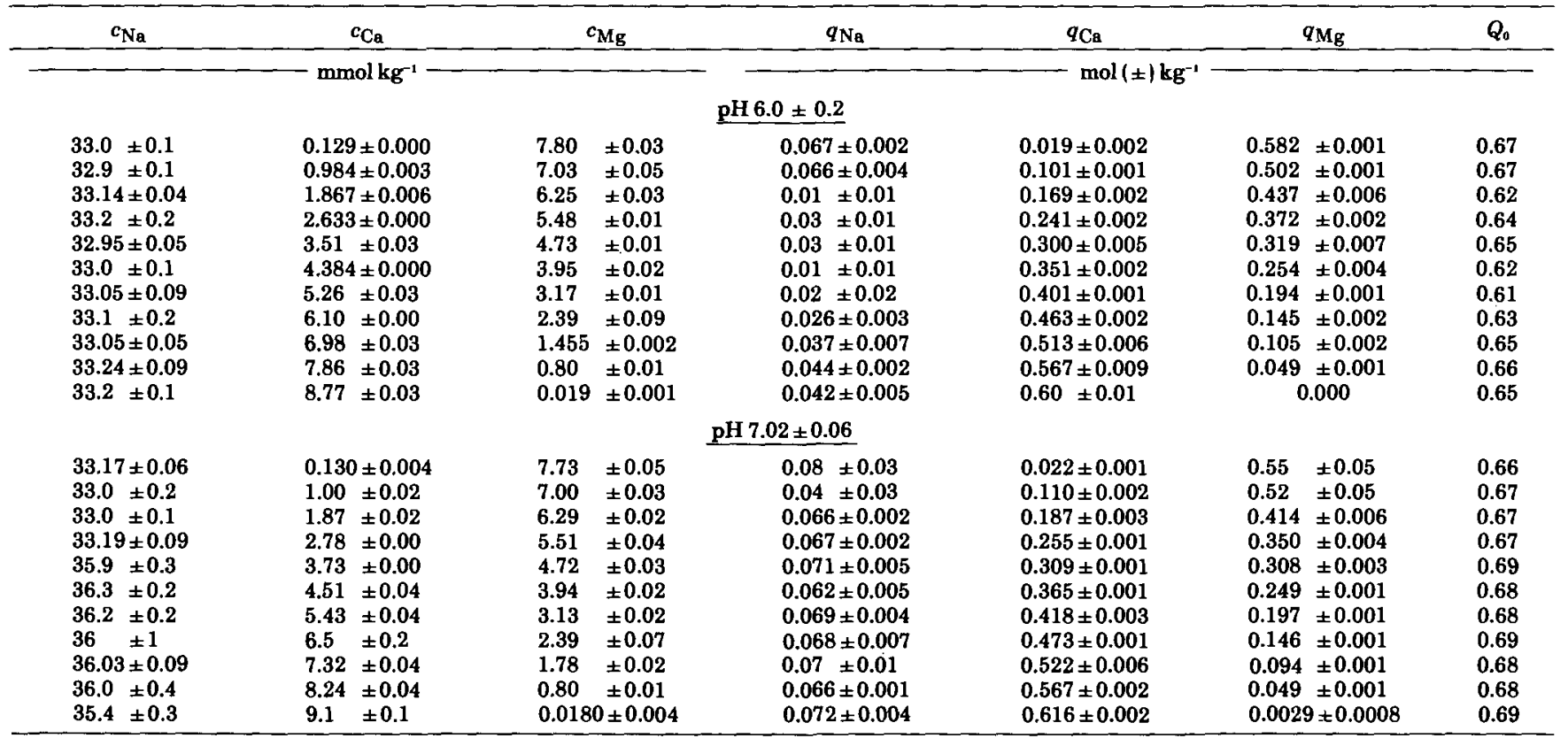

background medium, $Q_{0}$, was calculated with the equation:

$$
Q_{0}=\Gamma_{\mathrm{Na}}+2\left(\Gamma_{\mathrm{Ca}}+\Gamma_{\mathrm{Mg}}\right) \equiv q_{\mathrm{Na}}+q_{\mathrm{Ca}}+q_{\mathrm{Mg}}[1]
$$

where $\Gamma_{M}$ is a surface excess of metal $M(M=N a, C a$, or $\mathrm{Mg}$ ), in moles per kilogram of soil, and $q_{\mathrm{M}}$ is the corresponding number of moles of adsorbed metal charge per kilogram of soil. The charge fraction of each metal in the exchanger and aqueous solution phases were calculated with Eq. [2] in Fletcher et al. (1984). The fraction of adsorbed bivalent metal cation charge accounted for by $\mathrm{Mg}\left(E_{\mathrm{Mg}}^{\prime}\right)$ and the similar charge fraction for the aqueous solution phase $\left(\tilde{E}_{\mathrm{Mg}}^{\prime}\right)$ were calculated with the equation (Sposito et al., 1983):

Table 2-Experimental data on $\mathrm{Na}-\mathrm{Ca}-\mathrm{Mg}$ exchange at $\tilde{E}_{\mathrm{Na}}=0.85$ on Altamont soil.

\begin{tabular}{|c|c|c|c|c|c|c|}
\hline$c_{\mathrm{Na}}$ & ${ }^{c} \mathrm{Ca}$ & $c_{\mathbf{M g}}$ & $q_{\mathrm{Na}}$ & $q_{\mathrm{Ca}}$ & $q_{\mathrm{Mg}}$ & $Q_{0}$ \\
\hline \multicolumn{7}{|c|}{$\underline{\mathrm{pH}} 4.7 \pm 0.3$} \\
\hline $\begin{array}{l}46.0 \pm 0.2 \\
46.00 \pm 0.06 \\
46.0 \pm 0.2 \\
46.08 \pm 0.09 \\
46.21 \pm 0.05 \\
46.3 \pm 0.1 \\
46.18 \pm 0.05 \\
46.2 \pm 0.2 \\
46.3 \pm 0.2 \\
46.4 \pm 0.05 \\
46.1 \pm 0.2\end{array}$ & \begin{tabular}{l}
\multicolumn{1}{c}{0.000} \\
$0.548 \pm 0.003$ \\
$0.972 \pm 0.008$ \\
$1.42 \pm 0.02$ \\
$1.897 \pm 0.007$ \\
$2.348 \pm 0.002$ \\
$2.9 \quad \pm 0.1$ \\
$3.274 \pm 0.006$ \\
$3.76 \pm 0.02$ \\
$4.198 \pm 0.009$ \\
$4.69 \pm 0.02$
\end{tabular} & $\begin{array}{l}3.72 \pm 0.03 \\
3.43 \pm 0.04 \\
3.03 \pm 0.01 \\
2.62 \pm 0.02 \\
2.213 \pm 0.008 \\
1.880 \pm 0.007 \\
1.54 \pm 0.03 \\
1.123 \pm 0.007 \\
0.76 \pm 0.01 \\
0.392 \pm 0.002 \\
0.000\end{array}$ & 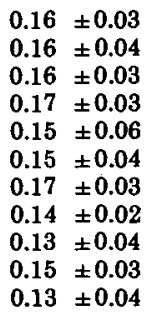 & \begin{tabular}{ll}
\multicolumn{1}{c}{0.000} \\
$0.0897 \pm 0.0007$ \\
0.16 & \pm 0.01 \\
0.206 & \pm 0.004 \\
0.251 & \pm 0.007 \\
0.298 & \pm 0.004 \\
0.34 & \pm 0.01 \\
0.386 & \pm 0.007 \\
0.393 & \pm 0.008 \\
0.43 & \pm 0.01 \\
0.470 & \pm 0.002
\end{tabular} & $\begin{array}{ll}0.46 & \pm 0.02 \\
0.391 & \pm 0.006 \\
0.342 & \pm 0.009 \\
0.304 & \pm 0.007 \\
0.255 & \pm 0.009 \\
0.202 & \pm 0.005 \\
0.148 & \pm 0.006 \\
0.116 & \pm 0.004 \\
0.074 & \pm 0.004 \\
0.042 & \pm 0.002 \\
0.000 & \end{array}$ & $\begin{array}{l}0.62 \\
0.64 \\
0.66 \\
0.68 \\
0.66 \\
0.65 \\
0.66 \\
0.65 \\
0.59 \\
0.63 \\
0.60\end{array}$ \\
\hline \multicolumn{7}{|c|}{$\underline{\mathrm{pH}} 5.8 \pm 0.1$} \\
\hline $\begin{array}{l}47.3 \pm 0.1 \\
47.2 \pm 0.1 \\
47.2 \pm 0.1 \\
47.4 \pm 0.1 \\
47.4 \pm 0.1 \\
47.2 \pm 0.2 \\
47.2 \pm 0.2 \\
47.1 \pm 0.1 \\
47.19 \pm 0.03 \\
47.09 \pm 0.09 \\
46.83 \pm 0.08\end{array}$ & \begin{tabular}{l}
\multicolumn{2}{c}{0.000} \\
$0.52 \pm 0.01$ \\
$0.93 \pm 0.01$ \\
$1.348 \pm 0.008$ \\
$1.777 \pm 0.007$ \\
$2.19 \pm 0.02$ \\
$2.63 \pm 0.01$ \\
$3.08 \pm 0.01$ \\
$3.50 \pm 0.01$ \\
$3.96 \pm 0.01$ \\
$4.370 \pm 0.003$
\end{tabular} & $\begin{array}{c}3.71 \pm 0.02 \\
3.35 \pm 0.01 \\
3.01 \pm 0.02 \\
2.61 \pm 0.01 \\
2.24 \pm 0.01 \\
1.88 \pm 0.01 \\
1.522 \pm 0.005 \\
1.122 \pm 0.003 \\
0.764 \pm 0.009 \\
0.387 \pm 0.000 \\
0.000\end{array}$ & $\begin{array}{l}0.183 \pm 0.006 \\
0.187 \pm 0.007 \\
0.165 \pm 0.002 \\
0.160 \pm 0.005 \\
0.184 \pm 0.003 \\
0.176 \pm 0.005 \\
0.156 \pm 0.006 \\
0.153 \pm 0.007 \\
0.16 \pm 0.01 \\
0.16 \pm 0.02 \\
0.166 \pm 0.004\end{array}$ & \begin{tabular}{ll}
\multicolumn{2}{c}{0.000} \\
$0.100 \pm 0.001$ \\
$0.159 \pm 0.001$ \\
$0.2148 \pm 0.0002$ \\
$0.266 \pm 0.001$ \\
$0.315 \pm 0.001$ \\
$0.352 \pm 0.003$ \\
$0.400 \pm 0.001$ \\
$0.439 \pm 0.003$ \\
$0.480 \pm 0.001$ \\
$0.522 \pm 0.005$
\end{tabular} & $\begin{array}{ll}0.481 & \pm 0.003 \\
0.412 & \pm 0.003 \\
0.352 & \pm 0.002 \\
0.303 & \pm 0.0003 \\
0.256 & \pm 0.001 \\
0.210 & \pm 0.001 \\
0.161 & \pm 0.003 \\
0.120 & \pm 0.001 \\
0.0789 & \pm 0.0003 \\
0.044 & \pm 0.003 \\
c & 0.000\end{array}$ & $\begin{array}{l}0.66 \\
0.70 \\
0.68 \\
0.68 \\
0.71 \\
0.70 \\
0.67 \\
0.67 \\
0.68 \\
0.69 \\
0.69\end{array}$ \\
\hline \multicolumn{7}{|c|}{$\underline{\mathrm{pH}} 6.9 \pm 0.2$} \\
\hline $\begin{array}{ll}39.7 & \pm 0.2 \\
39.8 & \pm 0.3 \\
39.7 & \pm 0.2 \\
39.8 & \pm 0.2 \\
39.2 & \pm 0.2 \\
39.7 & \pm 0.2 \\
39.6 & \pm 0.3 \\
39.6 & \pm 0.3 \\
39.7 & \pm 0.2 \\
39.8 & \pm 0.2 \\
39.7 & \pm 0.3\end{array}$ & $\begin{array}{c}3.68 \pm 0.06 \\
3.38 \pm 0.03 \\
2.98 \pm 0.03 \\
2.55 \pm 0.03 \\
2.23 \pm 0.02 \\
1.90 \pm 0.02 \\
1.52 \pm 0.01 \\
1.154 \pm 0.006 \\
0.794 \pm 0.009 \\
0.445 \pm 0.005 \\
0.000\end{array}$ & $\begin{array}{c}0.000 \\
0.388 \pm 0.002 \\
0.766 \pm 0.003 \\
1.07 \pm 0.02 \\
1.42 \pm 0.01 \\
1.86 \pm 0.03 \\
2.26 \pm 0.04 \\
2.61 \pm 0.03 \\
2.98 \pm 0.05 \\
3.36 \pm 0.05 \\
3.63 \pm 0.03\end{array}$ & $\begin{array}{l}0.144 \pm 0.004 \\
0.146 \pm 0.003 \\
0.146 \pm 0.006 \\
0.150 \pm 0.003 \\
0.155 \pm 0.003 \\
0.154 \pm 0.002 \\
0.156 \pm 0.004 \\
0.156 \pm 0.003 \\
0.191 \pm 0.004 \\
0.159 \pm 0.003 \\
0.163 \pm 0.002\end{array}$ & $\begin{array}{c}0.552 \pm 0.003 \\
0.500 \pm 0.005 \\
0.459 \pm 0.006 \\
0.409 \pm 0.003 \\
0.358 \pm 0.004 \\
0.317 \pm 0.002 \\
0.268 \pm 0.003 \\
0.211 \pm 0.002 \\
0.154 \pm 0.002 \\
0.0956 \pm 0.0007 \\
0.000\end{array}$ & $\begin{array}{l}0.000 \\
0.0501 \pm 0.0006 \\
0.098 \pm 0.001 \\
0.144 \pm 0.002 \\
0.196 \pm 0.002 \\
0.243 \pm 0.002 \\
0.299 \pm 0.002 \\
0.346 \pm 0.005 \\
0.406 \pm 0.005 \\
0.482 \pm 0.006 \\
0.596 \pm 0.003\end{array}$ & $\begin{array}{l}070 \\
0.70 \\
0.70 \\
0.70 \\
0.71 \\
0.71 \\
0.72 \\
0.71 \\
0.75 \\
0.74 \\
0.76\end{array}$ \\
\hline
\end{tabular}




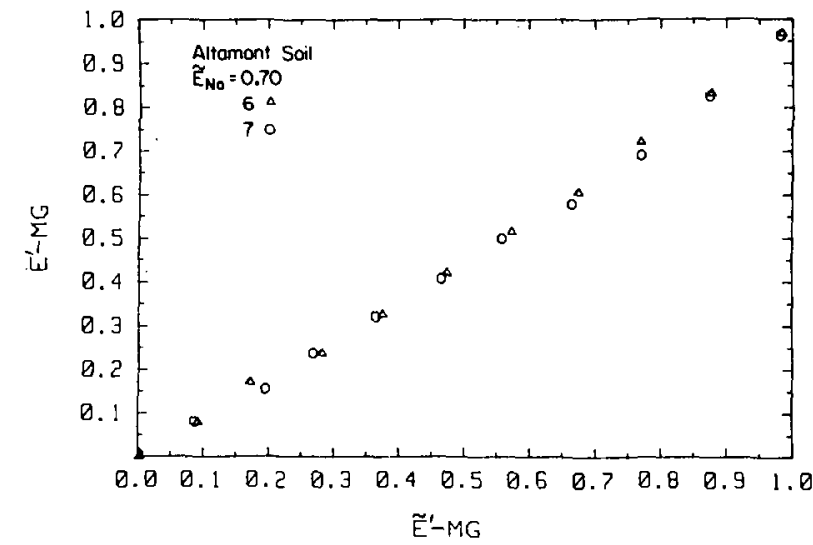

Fig. 1-Effect of pH on the $E_{\mathrm{M}_{8}}^{\prime}-\tilde{E}_{\mathrm{M}}^{\prime}$ relationship at $\tilde{E}_{\mathrm{Na}}=0.70$ for Altamont soil.

$E_{\mathrm{Mg}}^{\prime}=q_{\mathrm{Mg}} /\left(q_{\mathrm{Ca}}+q_{\mathrm{Mg}}\right) \quad \tilde{E}_{\mathrm{Mg}}^{\prime}=c_{\mathrm{Mg}} /\left(c_{\mathrm{Ca}}+c_{\mathrm{Mg}}\right)$

where $c_{M}$ is in $\mathrm{mmol} / \mathrm{kg}$ solution.

\section{RESULTS AND DISCUSSION}

The primary laboratory data from the ternary exchange experiments are listed in Tables 1 and 2 . In these tables, $c$ is an equilibrium millimolinity (millimoles per kilogram of solution) and $q$ is an adsorbed cation charge. The last column in each table gives values of the total adsorbed metal cation charge.

Figures 1 and 2 show plots of $E_{\mathrm{Mg}}^{\prime}$ against $\tilde{E}_{\mathrm{Mg}}^{\prime}$ for varying $\mathrm{pH}$ values at $\tilde{E}_{\mathrm{Na}}=0.70$ and 0.85 , respectively. For $\mathrm{Ca} \rightarrow \mathrm{Mg}$ exchange at $\tilde{E}_{\mathrm{Na}}=0.0$, this kind of plot is an exchange isotherm. The figures demonstrate clearly that, within the precision of the data, there is no effect of $\mathrm{pH}$ on the relationship between the Mg-fraction of the total bivalent cation charge on the exchanger and that in aqueous solution. This same result was found by Fletcher et al. (1984, Fig. 3) for $\mathrm{Ca} \rightarrow \mathrm{Mg}$ exchange at $\tilde{E}_{\mathrm{Na}}=0.0$ on the Altamont soil. The experiments at $\tilde{E}_{\mathrm{Na}}=0.70$ (Fig. 1) correspond to $\mathrm{E}_{\mathrm{Na}}=0.10 \pm 0.01$ and $0.05 \pm 0.03$ at pH 7 and 6 , respectively, whereas those at $\widetilde{\tilde{E}}_{\mathrm{Na}}=0.85$ (Fig. 2) correspond to $E_{\mathrm{Na}}=0.22 \pm 0.01,0.25 \pm 0.02$, and 0.24 \pm 0.02 at $\mathrm{pH} 7,6$, and 5 , respectively. Thus the $\mathrm{pH}-$ independence of the $\tilde{E}_{\mathrm{Mg}}^{\prime}-E_{\mathrm{Mg}}^{\prime}$ relation on the Altamont soil has been shown for ESP between 0 and $25 \%$. The sharp reduction in ESP from 10 to $5 \%$ at $\widetilde{E}_{\mathrm{Na}}=0.70$ as the $\mathrm{pH}$ value decreased from 7 to 6 also suggests a

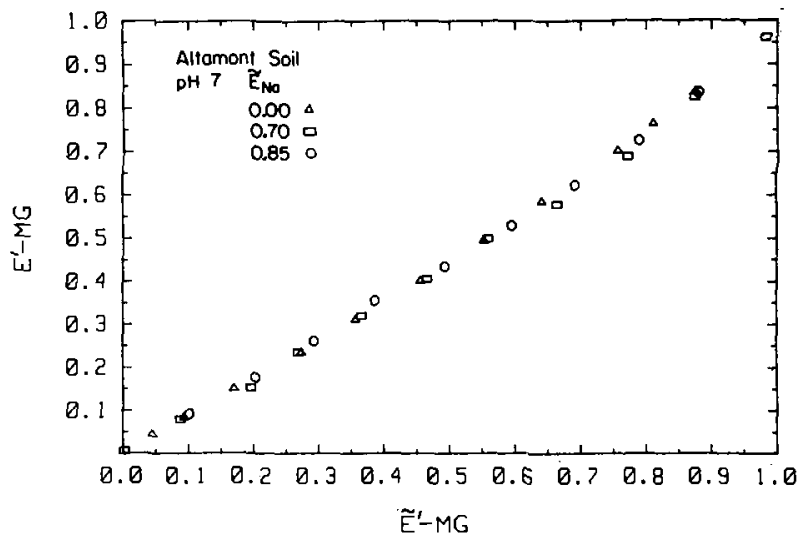

Fig. 3-Effect of $\tilde{E}_{\mathrm{Na}}$ on the $E_{\mathrm{Mq}}^{\prime}-\tilde{E}_{\mathrm{M}}^{\prime}$ relationship at pH 7 for $\mathrm{Al}$ tamont soil.

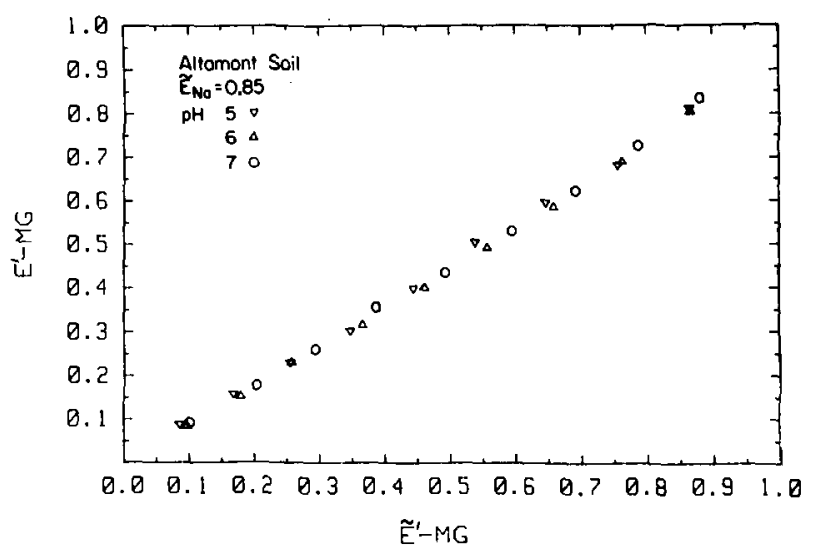

Fig. 2-Effect of $\mathrm{pH}$ on the $E_{\mathrm{Mq}}^{\prime}-\tilde{E}_{\mathrm{Mq}}^{\prime}$ relationship at $\tilde{E}_{\mathrm{Na}}=0.85$ for Altamont soil.

relatively low affinity of the Altamont soil separate for $\mathrm{Na}^{+}$in the face of competition by protons.

Figures 3 and 4 show plots of $E_{\mathrm{Mg}}^{\prime}$ against $\tilde{E}_{\mathrm{Mg}}^{\prime}$ at fixed $\mathrm{pH}$ values with varying $\tilde{E}_{\mathrm{Na}}$. At $\mathrm{pH} 7$ there is, within the precision of the experimental data, congruence of the three curves determined at $E_{\mathrm{Na}}=0.00$, 0.10 and 0.22 . Thus, for ESP values up to $22 \%$, the $\mathrm{E}_{\mathrm{Mg}}^{\prime}-\mathrm{E}_{\mathrm{Mg}}^{\prime}$ relationship at $\mathrm{pH} 7$ on the Altamont soil in a perchlorate background is invariant. The same conclusion can be drawn from Fig. 4 at pH 6 for ESP values up to $25 \%$. The ESP-independence of the $\mathrm{E}_{\mathrm{Mg}}^{\prime}$ $\tilde{\mathrm{E}}_{\mathrm{Mg}}^{\prime}$ relation was also found by Sposito et al. (1983, Fig. 1) on specimen montmorillonite at $\mathrm{pH} 7$ in 50 mol m-3 perchlorate. However, in that study, the isotherm was a C-curve (Sposito, 1981, Chapt. 5) indicating no preference for $\mathrm{Ca}$ over $\mathrm{Mg}$. In the present study, all of the isotherms lie somewhat below a Ccurve and, therefore, $\mathrm{Ca}$ is slightly preferred over $\mathrm{Mg}$ on the Altamont soil. This preference, as discussed by Fletcher et al. (1984), is consistent with the presence of organic matter in the soil.

If it is correct to assume that the surface-reactive portion of the Altamont soil suspension in the present experiments $(0 \leq \mathrm{ESP} \leq 25 \%)$ contained well-developed quasicrystals, as would exist in pure montmorillonite suspensions under the same conditions (Shainberg and Letey, 1984), then $\mathrm{Ca} \rightarrow \mathrm{Mg}$ exchange should have involved principally the interlayer sites

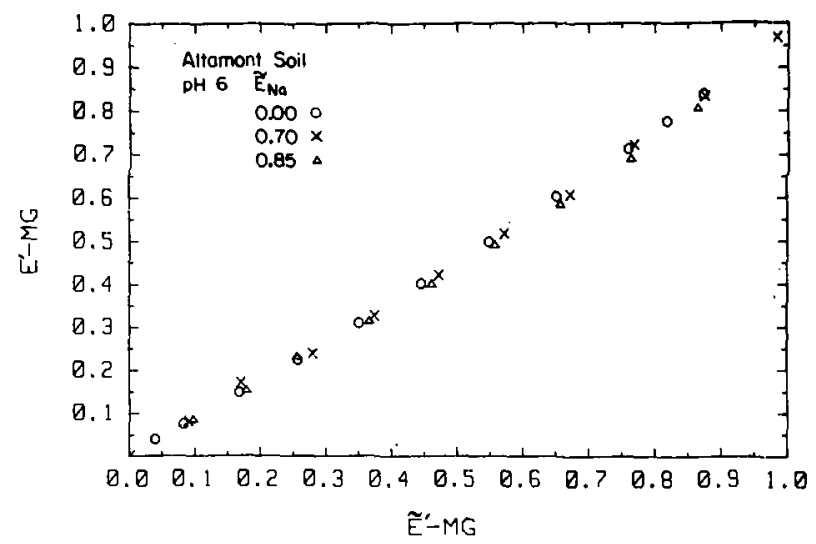

Fig. 4-Effect of $\tilde{E}_{\mathrm{Na}}$ on the $E_{\mathrm{M}_{\mathrm{z}}}^{\prime}-\tilde{E}_{\mathrm{M} z}^{\prime}$ relationship at pH 6 for Altamont soil. 
Table 3-Effects of $\mathrm{Mg}$ saturation and $\mathrm{pH}$ on $Q_{0}$, the total adsorbed metal cation charge.

\begin{tabular}{|c|c|c|c|c|c|c|c|}
\hline \multirow{2}{*}{$\begin{array}{c}E_{\mathrm{Na}:} \\
\mathrm{pH}: \\
Q_{0} \\
\end{array}$} & $\begin{array}{l}0.00^{\dagger} \\
7.0\end{array}$ & \multicolumn{2}{|c|}{$\begin{array}{l}0.22 \\
7.0\end{array}$} & \multicolumn{2}{|c|}{$\begin{array}{l}0.00 \dagger \\
6.0\end{array}$} & \multicolumn{2}{|c|}{$\begin{array}{l}0.05 \\
6.0\end{array}$} \\
\hline & $E_{M g}$ & $Q_{0}$ & $E_{M g}$ & $Q_{0}$ & $E_{\mathrm{Mg}}$ & $Q_{0}$ & $E_{\mathrm{Mg}}$ \\
\hline$\underset{\mathrm{kg}^{-1}}{\operatorname{mol}( \pm)}$ & & $\underset{\mathrm{kg}^{-1}}{\operatorname{mol}( \pm)}$ & & $\underset{\mathrm{kg}^{-3}}{\operatorname{mol}( \pm)}$ & & $\underset{\mathbf{k g}^{-1}}{\operatorname{mol}( \pm)}$ & \\
\hline 0.64 & 0.04 & 0.70 & 0.00 & 0.48 & 0.04 & 0.65 & 0.00 \\
\hline 0.65 & 0.08 & 0.70 & 0.07 & 0.50 & 0.07 & 0.66 & 0.08 \\
\hline 0.68 & 0.15 & 0.70 & 0.14 & 0.53 & 0.15 & 0.65 & 0.16 \\
\hline 0.70 & 0.24 & 0.70 & 0.21 & 0.56 & 0.22 & 0.63 & 0.23 \\
\hline 0.69 & 0.31 & 0.71 & 0.28 & 0.56 & 0.31 & 0.61 & 0.32 \\
\hline 0.69 & 0.40 & 0.71 & 0.34 & 0.58 & 0.40 & 0.62 & 0.42 \\
\hline 0.69 & 0.49 & 0.72 & 0.41 & 0.58 & 0.50 & 0.65 & 0.49 \\
\hline 0.68 & 0.59 & 0.71 & 0.49 & 0.58 & 0.60 & 0.64 & 0.58 \\
\hline 0.70 & 0.70 & 0.75 & 0.54 & 0.59 & 0.71 & 0.62 & 0.71 \\
\hline 0.73 & 0.76 & 0.74 & 0.65 & 0.60 & 0.78 & 0.67 & 0.75 \\
\hline 0.75 & 0.84 & 0.76 & 0.79 & 0.61 & 0.84 & 0.67 & 0.87 \\
\hline
\end{tabular}

† Data from Table 5 of Fletcher et al. (1984).

with little or no competition from $\mathrm{Na}^{+}$residing primarily on external surfaces. This hypothesis, based on a high bivalent cation selectivity on the internal surfaces of quasicrystals, is in agreement with the data in Fig. 3 and 4. On the other hand, the data also support a selectivity of organic matter for bivalent cations relative to $\mathrm{Na}^{+}$. Both sources of bivalent cation exchange selectivity likely contribute to the ESP independence indicated in Fig. 3 and 4.

To the extent that stable quasicrystals (which require ESP $<15 \%$ ) existed in the surface-reactive portion of the soil suspension at $\widetilde{E}_{\mathrm{Na}}=0.70$ and induced exchangeable $\mathrm{Na}^{+}$to reside principally on external surfaces, the pH effect on ESP, noted above, can be interpreted as evidence for organic matter with its $\mathrm{pH}$ dependent charge also being bound to external surfaces. If external surfaces are primary sites for bound organic matter, then the Ca-selectivity apparent in Fig. 1 to 4 could be attributed to $\mathrm{Na}-\mathrm{Ca}-\mathrm{Mg}$ exchange com- petition on these surfaces. The interlayer surfaces would be largely free of organic matter, as might be supposed for optimal quasicrystal formation, and no selectivity for $\mathrm{Ca}$ would derive from them, as shown by Sposito et al. (1983) for specimen montmorillonite. This hypothesis certainly will require further experimentation to test its correctness. It is consistent, however, with the bivalent cation effects on $Q_{0}$ observed by Fletcher et al. (1984, Fig. 4) in $\mathrm{Na} \rightarrow \mathrm{Ca}$ and $\mathrm{Na}$ $\rightarrow \mathrm{Mg}$ exchanges on the Altamont soil, in that $Q_{0}$ remained constant once $E_{\mathrm{M}}(\mathrm{M}=\mathrm{Ca}$ or $\mathrm{Mg})$ reached the threshold value of 0.6 for stable quasicrystal formation.

\section{ACKNOWLEDGMENT}

The research reported here was supported in part by a grant from the Kearney Foundation of Soil Science.

\section{REFERENCES}

1. Bresler, E., G.L. McNeal, and D.L. Carter. 1982. Saline and sodic soils. Springer-Verlag, New York.

2. Fletcher, P., G. Sposito, and C.S. LeVesque. 1984. Sodiumcalcium-magnesium exchange reactions on a montmorillonite soil: I. Binary exchange reactions. Soil Sci. Soc. Am. J. 48:10161021 (this issue).

3. Levy, R., K.K. Tanji, and L.D. Whittig. 1983. Effect of precipitation of alkaline earth carbonates and magnesium hydroxide on Na-Ca-Mg exchange in Wyoming bentonite. Soil Sci. Soc. Am. J. 47:906-912.

4. Robbins, C.W., J.J. Jurinak, and R.J. Wagenet. 1980. Calculating cation exchange in a salt transport model. Soil Sci. Soc. Am. J. 44:1195-1200.

5. Shainberg, I., and J. Letey. 1984. Response of soils to sodic and saline conditions. Hilgardia 52:1-57.

6. Sposito, G. 1981. The thermodynamics of soil solutions. Clarendon Press, Oxford, UK

7. Sposito, G., K.M. Holtzclaw, C.T. Johnston, and C.S. LeVesque. 1981. Thermodynamics of sodium-copper exchange on Wyoming bentonite at $298 \mathrm{~K}$. Soil Sci. Soc. Am. J. 45:1079-1084.

8. Sposito, G., C. Jouany, K.M. Holtzclaw, and C.S. LeVesque. 1983. Calcium-magnesium exchange on Wyoming bentonite in the presence of adsorbed sodium. Soil Sci. Soc. Am. J. 47:10811085 . 